\title{
Short communication: Detection of Shiga toxin-producing Escherichia coli (STEC) in healthy cattle and pigs in Lima, Peru ${ }^{1}$
}

\author{
F. P. Rivera, ${ }^{\star}$ E. Sotelo, ${ }^{*}$ I. Morales, ${ }^{*}$ F. Menacho, ${ }^{*}$ A. M. Medina, ${ }^{\star}$ R. Evaristo, ${ }^{\star}$ R. Valencia, ${ }^{*}$ L. Carbajal, ${ }^{*}$ \\ J. Ruiz,†‡ and T. J. Ochoa* $\aleph^{2}$ \\ *Universidad Peruana Cayetano Heredia, Av. Honorio Delgado 430, San Martin de Porres, Lima 31, Peru \\ †Centre de Recerca en Salut Internacional de Barcelona, Hospital Clinic/Institut d'Investigacions Biomèdiques August Pi i Sunyer, \\ Universitat de Barcelona, C/Rosselló 132, 4. 08036, Barcelona, Spain \\ ¥Consorcio de Investigación Biomédica en Red de Epidemiología y Salud Pública, Spain \\ $\S$ University of Texas School of Public Health, Houston 77030
}

\section{ABSTRACT}

The aim of this study was to determine the prevalence of Shiga toxin-producing Escherichia coli (STEC) in cattle and pigs as a possible STEC reservoir in Lima, Peru. One hundred and fourteen cattle and 112 pigs from 10 and 4 farms, respectively, were studied. Five E. coli colonies per culture were studied by a multiplex real-time PCR to identify Shiga toxin-producing (stx1, stx2, eaeA), enterotoxigenic (lt, st), enteropathogenic (eaeA), enteroinvasive (ipaH), enteroaggregative $(a g g R)$, and diffusely adherent E. coli (daaD). Shiga toxin-producing $E$. coli were isolated from 16 cattle $(14 \%)$ but none from pigs. stx1 was found in all bovine isolates, 11 of which also carried eaeA genes (69\%); only 1 sample had both stx1 and stx2. Thirteen stxpositive strains were classified as Shiga-toxigenic (81\%) using an enzymatic immunoassay, 2 STEC strains were from serogroup 0157 (13\%), and 7 were sorbitol negative (44\%). Enteropathogenic E. coli were detected more frequently in cattle $(18 \%, 20 / 114)$ than in pigs $(5 \%, 6 / 112)$. To our knowledge, this is the first study on the prevalence of STEC in farms animals in Peru using molecular methods. Further studies are needed in a large number of farms to determine the relevance of these findings and its consequences for public health.

Key words: Shiga toxin-producing Escherichia coli, cattle, pig, Peru

\section{Short Communication}

Shiga toxin-producing Escherichia coli (STEC), also called verotoxin-producing $E$. coli (VTEC), is a group of foodborne pathogens that can cause severe human disease, such as hemolytic uremic syndrome (HUS),

Received June 28, 2011.

Accepted November 13, 2011.

${ }^{1}$ No conflict of interest exists for any of the authors.

${ }^{2}$ Corresponding author: Theresa.J.Ochoa@uth.tmc.edu particularly when the serotype is O157:H7. The most commonly assayed virulence factors of STEC are the 2 phage-encoded cytotoxins, called Shiga toxin 1 and 2 (encoded by the stx1 and stx2 genes, respectively), and the protein intimin (encoded by the chromosomal gene eae), which is responsible for the intimate attachment of the bacteria to intestinal epithelial cells.

Shiga toxin-producing $E$. coli have been found in the fecal flora of a wide variety of animals, including cattle, sheep, goats, pigs, cats, dogs, chickens, and gulls (Caprioli et al., 2005). The most important animal species in terms of human infection are cattle and pigs (Caprioli et al., 2005). High rates of colonization of STEC isolates have been found in bovine herds in many countries (Karmali et al., 2010). These rates are typically in the range of 10 to $25 \%$. Shiga toxin-producing $E$. coli strains are usually isolated from healthy animals but may be associated with an initial episode of diarrhea in young animals, followed by asymptomatic colonization. The isolation rates of $\mathrm{O} 157$ are much lower than those of non-O157 serotypes (Karmali et al., 2010).

Although STEC strains that cause human infections belong to a large number of $\mathrm{O}: \mathrm{H}$ serotypes, most outbreaks and sporadic cases of hemorrhagic colitis and HUS have been attributed to strains belonging to the enterohemorrhagic serotype O157:H7. As non-O157 STEC are more prevalent in animals and as contaminants in foods, humans are probably exposed more often to these strains. However, environmental samples including stool samples from farm animals are not routinely evaluated for these pathogens in veterinary laboratories outside the research setting.

In Peru, STEC is responsible for $0.4 \%$ of watery diarrhea cases in children in the community setting (Contreras et al., 2011), and 9\% of bloody diarrhea cases in children at the emergency room in Lima (A. Llanos, Universidad Peruana Cayetano Heredia, Lima, Peru, personal communication). The most common STEC serotype in Peru is O26:H11; and the most common seropathotype is B (45\%; Contreras et al., 2011). Ad- 
ditionally, in our experience, HUS is common in Peru; we have identified 188 HUS cases in a retrospective case series during the past $10 \mathrm{yr}$ at one pediatric hospital in Lima (T. Ochoa, unpublished data). However, no information exists on the prevalence, virulence factors, or serogroup of STEC strains isolated from farm animals. Therefore, the aims of this study were (1) to determine the prevalence of STEC in healthy cattle and pigs from Lima, Peru, (2) to determine the critical virulence factors (stx1, stx2, and eae) of the isolated STEC strains, and (3) to determine the serogroup O157 distribution of the STEC isolated strains.

This was a prospective, cross-sectional, descriptive study. Between November and December 2010, samples were collected from 114 cattle ( 2 mo to $8 \mathrm{yr}$ old) and 112 pigs (2 to 24 mo old). Cattle were screened from 10 dairy farms in the Quilmaná and San Fernando Districts, both in Cañete Province (average of 11 cattle per farm). Pigs were screened from 4 farms in Puente Piedra District in Lima Province (average of 28 pigs per farm). These cattle and pig farms were geographically separate. All animals in this study were healthy and without treatment with antibiotics or other drugs. Both the dairies and pig farms were exposed to the same weather and were fed similar diets. Rectal swabs of rectal feces were collected following previously described procedures (Rice et al., 2003) and placed in a Cary-Blair transport medium.

Samples were cultured on MacConkey agar plates for isolation of E. coli colonies. Detection of STEC and other diarrheagenic E. coli was done at the Tropical Medicine Institute Alexander von Humboldt in Lima. Five lactose-positive E. coli colonies per animal were isolated from MacConkey agar plates and analyzed by a multiplex real-time PCR method using previously validated specific primers for each pathotype: enteroaggregative $(\mathrm{a} g g \mathrm{R})$, enterotoxigenic $(l t, s t)$, enteropathogenic (eaeA alone), enteroinvasive $(i p a \mathrm{H})$, diffusely adherent E. coli (daaD), and STEC (stx1, stx2, eaeA; Guion et al., 2008). The STEC or Enteropathogenic E. coli (EPEC) isolates were biochemically confirmed to be $E$. coli by conventional biochemical tests. The somatic $(\mathbf{O})$ antigen 157 of STEC strains was determined by conventional serological methods using an $E$. coli antisera kit (Difco Laboratories Inc., Detroit, MI) following the manufacturer's instructions. Additionally, all STEC-positive colonies per animal were cultured on MacConkey sorbitol agar plates and all of 5 colonies, as pool, were tested for Shiga toxin expression with the Premier enterohemorrhagic E. coli (EHEC) enzymatic immunoassay Shiga-toxin test kit (Meridian Diagnostics Inc., Cincinnati, OH) following the manufacturer's instructions. The study was approved by the Animal Ethics Research Institutional Committee at Universidad Peruana Cayetano Heredia, Lima, Peru. We found STEC in 16 out of 114 (16\%) cattle stool samples and none from pig stool samples. Shiga toxin-producing $E$. coli isolation varied from 0 to $33 \%$ in each farm (Table 1). The STEC strains tended to be isolated more frequently in cattle younger than 24 mo of age than in older cows (20 vs. $6 \%$ ); however, this difference was not significant. The stx1 gene was found in all STEC isolates, 11 of which also carried eaeA genes (69\%). Only 1 sample was found to have both Shiga-toxin genes (stx1 and stx2; Table 2). Among PCR-positive STEC strains, 13 stx-positive strains were classified as Shiga-toxigenic (81\%) using an enzymatic immunoassay. Only 2 STEC strains were positive for the O157 serogroup (13\%); 1 strain was $s t x 1+/ e a e-$ and the other stx1+/eae+. Both E. coli O157 isolates were Shiga-toxigenic. Seven STEC-positive samples were sorbitol negative (44\%).

Enteropathogenic E. coli were detected more frequently in cattle $(18 \%, 20 / 114)$ than pigs $(5 \%, 6 / 112 ; P$ $<0.01$; Table 1). Enteropathogenic E. coli tended to be detected more frequently in cattle younger than 24 mo of age than in older cows (21\% vs. $13 \%)$. None of the other categories of diarrheagenic E. coli were detected.

The prevalence of STEC in dairy cattle from other countries of the world is highly variable. Caution is necessary when comparing prevalences because variations may be due to multiple factors, including number of animals screened, type and age of animals, sampling method, methodology used for processing of samples, and season in which the study is performed (Faith et al., 1996). In addition, fecal shedding by dairy cattle may be related to management strategies, including hygiene, diet, husbandry, and changes in housing or structure of the herd (Menrath et al., 2010).

Table 1. Shiga toxin-producing Escherichia coli (STEC) and enteropathogenic E. coli (EPEC) isolation in cattle and pigs in Lima, Peru

\begin{tabular}{llccrr}
\hline $\begin{array}{l}\text { Farm } \\
\text { animal }\end{array}$ & Location & $\begin{array}{c}\text { Number } \\
\text { of farms }\end{array}$ & $\begin{array}{c}\text { Number } \\
\text { of animals }\end{array}$ & $\begin{array}{c}\text { STEC } \\
{[\mathrm{n}(\%)]}\end{array}$ & $\begin{array}{r}\text { EPEC } \\
{[\mathrm{n}(\%)]}\end{array}$ \\
\hline Cattle & San Fernando District, Cañete Province & 7 & 61 & $13(21)$ & $14(23)$ \\
& Quilmaná District, Cañete Province & 3 & 53 & $3(6)$ & $6(11)$ \\
& Total & 10 & 114 & $16(14)$ & $20(18)$ \\
Pig & Puente Piedra District, Lima Province & 4 & 112 & 0 & $6(5)$ \\
\hline
\end{tabular}


Table 2. Genotypic and phenotypic characteristics of Shiga toxin-producing Escherichia coli (STEC) strains isolated from cattle in Lima, Peru

\begin{tabular}{|c|c|c|c|c|c|c|}
\hline Strain & \multicolumn{3}{|c|}{ Virulence gene $^{1}$} & $\begin{array}{l}\text { Shiga-toxin } \\
\text { production }^{2}\end{array}$ & $\begin{array}{c}\text { O157 } \\
\text { serogroup }^{3}\end{array}$ & $\begin{array}{c}\text { MacConkey } \\
\text { sorbitol negative }\end{array}$ \\
\hline CE-004 & + & - & + & + & - & + \\
\hline CE-006 & + & - & + & + & - & - \\
\hline CE-009 & + & - & + & + & - & - \\
\hline CE-012 & + & - & + & + & - & - \\
\hline CE-025 & + & - & - & + & + & + \\
\hline CE-041 & + & - & - & - & - & - \\
\hline CE-044 & + & - & + & + & - & + \\
\hline CE-048 & + & - & + & + & + & + \\
\hline CE-053 & + & - & + & + & - & + \\
\hline CE-054 & + & - & + & + & - & + \\
\hline CE-085 & + & - & + & - & - & + \\
\hline
\end{tabular}

${ }^{1}$ stx 1 = Shiga-toxin 1 gene; stx2 = Shiga-toxin 2 gene; eae = intimin gene; + indicates that the gene was detected by PCR; - indicates that the gene was not detected by PCR.

${ }^{2}$ Shiga-toxin production tested by Premier enterohemorrhagic E. coli (EHEC) enzymatic immunoassay (Meridian Diagnostics Inc., Cincinnati, $\mathrm{OH})$.

${ }^{3}$ Determination of the somatic (O) antigen type using an E. coli antisera kit (Difco Laboratories Inc., Detroit, MI).

In this study, STEC prevalence (14\%) was lower than found in some Latin American countries such as Argentina (43\%; Borie et al., 1997) and Chile (34.5\%; Fernández et al., 2009). However, there are countries with lower prevalence, including Brazil (10\%; AidarUgrinovich et al., 2007) and Venezuela (1.9\%; NarváezBravo et al., 2007). In the current study, STEC strains tended to be isolated more frequently from cattle younger than 24 mo of age (20\%). Calves have been considered the bovine category with the highest prevalence of STEC (Nielsen et al., 2002), although some have found the highest prevalence in heifers (Cobbold and Desmarchelier, 2000). The reasons for this difference between age groups are unknown but might reflect differences in ruminant development, immune response, diet, aspects of cattle management, and other factors (Heuvelink et al. 1998).

Although some Shiga toxin 1-positive STEC isolates have previously been associated with severe disease (Brooks et al., 2005), epidemiological studies have demonstrated that Shiga toxin 2 is the most important virulence factor associated with severe human disease and is significantly associated with an increased risk of HUS in persons infected with O157 or non-O157 STEC (Brooks et al., 2005). In the present study, only 2 STEC strains harbored the stx2 gene. This finding is consistent with our previous studies in Peruvian children in which STEC strains expressing only Shiga toxin 1 are highly prevalent in children with diarrhea (Contreras et al., 2011).
We detected EPEC in $18 \%$ of cattle and $5 \%$ of pigs. It is known that stx genes are carried by lysogenic bacteriophages and can be acquired by horizontal gene transfer (Muniesa and Jofre, 2000). Therefore, it has been suggested that the emergence of enterohemorrhagic $E$. coli strains has resulted from successive horizontal transfers of virulence factors between STEC and EPEC (Caprioli et al., 2005). It is known that fecal pollution of water is one of the most important routes of STEC transmission. Thus, improved wastewater treatment could be appropriate for reducing the survival of STEC and other eae+ E. coli. Contamination of the environment, followed by uptake of STEC by farm animals on pasture, maintains the epidemiological cycle of STEC and is a public health concern.

Our study has some methodological limitations. We did not use a method to improve the detection of STEC from stool samples, such as subculture on cefixime tellurite sorbitol MacConkey (CT-SMAC) agar or immunomagnetic separation, so it is possible that our findings underestimate the number of $\mathrm{O} 157$ STEC strains. Because this was a cross-sectional study focused on a short time interval, we cannot address STEC prevalence during other months or seasonality. In summary, STEC were isolated more frequently from younger cattle; Shiga toxin 1 was the most common toxin type, and only $13 \%$ were O157 positive. Shiga toxin-producing $E$. coli were not isolated from pigs. These data are relevant in estimating the local STEC prevalence in farm animals. Further studies are needed 
to determine the prevalence in a larger number of samples and to implement strategies to minimize the risk of infection spreading to humans.

\section{ACKNOWLEDGMENTS}

This work was partially funded by Agencia Española de Cooperación Internacional para el Desarrollo (AECID), Spain, Programa de Cooperación Interuniversitaria e Investigación Científica con Iberoamérica (D/019499/08 and D/024648/09); National Institutes of Health, Public Health Service awards 1K01TW007405 (T. J. Ochoa); and by Fondo de Investigaciones Sanitarias, Spain, CP05/0130 (J. Ruiz). We thank María Bernal and Rina Meza (US Naval Medical Research Unit6, Lima, Peru), for technical assistance at NAMRU-6 and Mac Fulton Rivera Guerrero (Asociación Ganadera Provincial de Yauyos, Lima, Peru) for identifying the farms for the study.

\section{REFERENCES}

Aidar-Ugrinovich, L., J. Blanco, M. Blanco, J. E. Blanco, L. Leomil, G. Dahbi, A. Mora, D. L. Onuma, W. D. Silveira, and A. F. Pestana de Castro. 2007. Serotypes, virulence genes, and intimin types of Shiga toxin-producing Escherichia coli (STEC) and enteropathogenic E. coli (EPEC) isolated from calves in São Paulo, Brazil. Int. J. Food Microbiol. 115:297-306.

Borie, C. F., Z. Monreal, J. Martinez, C. Arellano, and V. Prado. 1997. Detection and characterization of enterohaemorrhagic Escherichia coli in slaughtered cattle. Zentralbl. Veterinarmed. B. 44:273-279.

Brooks, J. T., E. G. Sowers, J. G. Wells, K. D. Greene, P. M. Griffin, R. M. Hoekstra, and N. A. Strockbine. 2005. Non-O157 Shiga toxin-producing Escherichia coli infections in the United States, 1983-2002. J. Infect. Dis. 192:1422-1429.

Caprioli, A., S. Morabito, H. Brugère, and E. Oswald. 2005. Enterohaemorrhagic Escherichia coli: Emerging issues on virulence and modes of transmission. Vet. Res. 36:289-311.

Cobbold, R., and P. Desmarchelier. 2000. A longitudinal study of Shiga-toxigenic Escherichia coli (STEC) prevalence in three Australian dairy herds. Vet. Microbiol. 71:125-137.
Contreras, C. A., T. J. Ochoa, J. Ruiz, D. W. Lacher, F. P. Rivera, Y. Saenz, E. Chea-Woo, N. Zavaleta, A. I. Gil, C. F. Lanata, L. Huicho, R. C. Maves, C. Torres, C. DebRoy, and T. G. Cleary. 2011. Phylogenetic relationships of Shiga toxin-producing Escherichia coli isolated from Peruvian children. J. Med. Microbiol. 60:639-646.

Faith, N. G., J. A. Shere, R. Brosch, K. W. Arnold, S. E. Ansay, M. S. Lee, J. B. Luchansky, and C. W. Kaspar. 1996. Prevalence and clonal nature of Escherichia coli $\mathrm{O} 157: \mathrm{H} 7$ on dairy farms in Wisconsin. Appl. Environ. Microbiol. 62:1519-1525.

Fernández, D., E. M. Rodríguez, G. H. Arroyo, N. L. Padola, and A. E. Parma. 2009. Seasonal variation of Shiga toxin-encoding genes (stx) and detection of E. coli $\mathrm{O} 157$ in dairy cattle from Argentina. J. Appl. Microbiol. 106:1260-1267.

Guion, C. E., T. J. Ochoa, C. M. Walker, F. Barletta, and T. G. Cleary. 2008. Detection of diarrheagenic Escherichia coli by use of melting-curve analysis and real-time multiplex PCR. J. Clin. Microbiol. 46:1752-1757.

Heuvelink, A. E., F. L. A. M. van den Biggelaar, J. T. M. ZwartkruisNahuis, R. G. Herbes, R. Huyben, N. Nagelkerke, W. J. Melchers, L. A. H. Monnens, and E. de Boer. 1998. Occurrence of verocytotoxin-producing Escherichia coli $\mathrm{O} 157$ on Dutch dairy farms. J. Clin. Microbiol. 36:3480-3487.

Karmali, M. A., V. Gannon, and J. M. Sargeant. 2010. Verocytotoxinproducing Escherichia coli (VTEC). Vet. Microbiol. 140:360-370.

Menrath, A., L. H. Wieler, K. Heidemanns, T. Semmler, A. Fruth, and N. Kemper. 2010. Shiga toxin producing Escherichia coli: Identification of non-O157:H7-Super-Shedding cows and related risk factors. Gut Pathog. 2:7.

Muniesa, M., and J. Jofre. 2000. Occurrence of phages infecting Escherichia coli $\mathrm{O} 157: \mathrm{H} 7$ carrying the Stx 2 gene in sewage from different countries. FEMS Microbiol. Lett. 183:197-200.

Narváez-Bravo, C. A., G. Carruyo-Núñez, M. Moreno, A. RodasGonzález, A. E. Hoet, and T. E. Wittum. 2007. Aislamiento de Escherichia coli $\mathrm{O} 157: \mathrm{H} 7$ en muestras de heces de ganado bovino doble propósito del municipio de Miranda, Estado Zulia, Venezuela. Rev. Científica (Maracaibo) 17:239-245.

Nielsen, E. M., C. Tegtmeier, H. J. Andersen, C. Grønbæk, and J. S. Andersen. 2002. Influence of age, sex and herd characteristics on the occurrence of verocytotoxin-producing Escherichia coli $\mathrm{O} 157$ in Danish dairy farms. Vet. Microbiol. 88:245-257.

Rice, D. H., H. Q. Sheng, S. A. Wynia, and C. J. Hovde. 2003. Rectoanal mucosal swab culture is more sensitive than fecal culture and distinguishes Escherichia coli O157:H7-colonized cattle and those transiently shedding the same organism. J. Clin. Microbiol. 41:4924-4929. 